\section{SUPREMELY EFFECTIVE CLOTHS}

Evident's range of re-usable, washable microfibre cloths, 'e-cloth Professional', contain antibacterial nano silver and clean so effectively that there is nowhere left for bacteria to grow, removing grease, dirt and bacteria from hard surfaces without the need for harsh, needlessly expensive cleaning products.

HTM 01-05 section 6.58 details

Department of Health-sponsored research on the use of microfibre cloths suggesting that, provided deep cleaning is performed as an initial exercise, the subsequent use of microfibre-based techniques can be helpful in achieving satisfactory removal of infectious agents from surfaces. Additionally it states, 'The patient treatment areas should be cleaned after every session using disposable cloths or clean microfibre materials'

Following National Patient Safety Agency guidelines e-cloth Professional cloths are available in packs of ten in green, blue, red or yellow.

Reader response number 58

\section{INTELLIGENT ULTRASONIC DEVICE}

With PerioScan, Sirona is offering an intelligent ultrasonic device that supports the task of root planing and scaling, combining diagnosis and therapy at the same time: subgingival calculus can be detected and removed quickly and precisely without changing instruments. An additional advantage of PerioScan is the gentle and painless treatment due to the controlled linear vibrations of the ultrasonic tip.

Effective bacteria management is crucial, ensuring the long term success of the periodontal treatment. Both the SIROLaser Advance and its little brother, the basic model SIROLaser Xtend, reduce germs in the affected gingival pockets, ensuring a sustained improvement in periodontal treatments. The diode laser is intuitively operated and easy to configure to the user's requirement thanks to its intelligent software with self-explanatory menu navigation and practical colour touchscreen.

With its high quality handpieces and contra-angles as well as ultrasonic instruments and air scalers, Sirona supports dental technical staff in the areas of diagnosis, cleaning, treatment and polishing. Suitable instruments are available for all cleaning and polishing services and all prophylaxis instruments from Sirona are ready for use in seconds after their easy connection. Reader response number 59

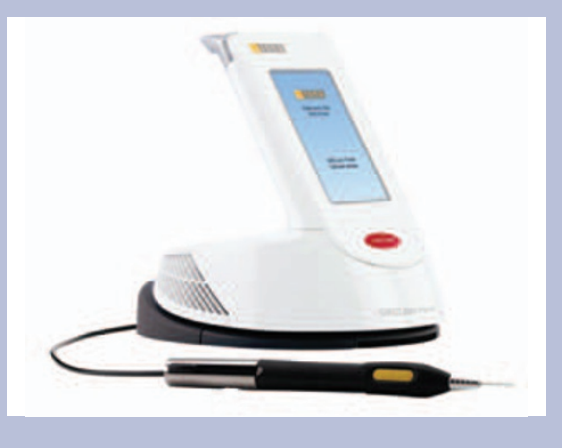

\section{ACHIEVE A HIGH LUSTRE}

Being disposable, One Gloss polishers are the perfect adjunct to your cross infection procedures.

These unique one-step polishers can be used to finish and polish all composite restorations simply by altering the contact pressure on the restoration, without having to change instrument. To achieve a high lustre finish to your composite restorations simply apply pressure to the instrument and during the polishing process gradually reduce the pressure for an unrivalled glossy finish.

One Gloss polishers are extremely useful for removing surface stains as well as excess resin cement from tooth surfaces without causing any damage to the enamel. These polishers have proved to be particularly useful in orthodontic cases and polishing after scaling. By using One Gloss before tooth whitening treatments chairside time is greatly reduced.

One Gloss is packaged in a set of 60 polishers (20 each of Cup, Midi Point and Inverted Cone shapes) and 3 x CA Mandrels plus instructions. Reader response number 61

\section{STATE-OF-THE-ART DENTAL SETS}

Plinth Dental have launched two stateof-the-art dental sets from top manufacturer, Gnatus. The top-line Syncrus HLX Full dental set comes complete with ergonomic, fully adjustable dental chair, integrated foot control for all major functions, autoclavable dental delivery unit for syringe and handpieces, a water unit with removable filter, dental light with five LEDs and matching, heightadjustable dental stool, all for around $£ 6,500$ (ex VAT). The budget priced POP Star LSF dental set offers practicality, ergonomics and modern styling at just $£ 2,200$ and again comes complete with chair, delivery unit, water receptacle, dental light and matching stool.

All the equipment is delivered and supported direct from the UK, with factory-trained technicians providing after-care and maintenance.

Reader response number 62 